\title{
Modelling and Simulation of a Microturbine during Transient Events
}

\author{
P. Eguia ${ }^{1}$, I. Zamora ${ }^{1}$, E. Torres ${ }^{1}$, J.I. San Martín ${ }^{1}$, M. Moya ${ }^{2}$, J.C. Bruno ${ }^{2}$, A. Coronas ${ }^{2}$ \\ ${ }^{1}$ Department of Electrical Engineering \\ E.T.S.I., University of the Basque Country UPV/EHU \\ Alda. Urquijo s/n, 48013 Bilbao (Spain) \\ Phone: 0034 946017332, e-mail: pablo.eguia@ehu.es, inmaculada.zamora@ehu.es, esther.torresi@ehu.es, \\ joseignacio.sanmartin@ehu.es \\ ${ }^{2}$ CREVER Dept. of Mechanical Engineering, Universitat Rovira i Virgili \\ Av. Paisos Catalans, 26, 43007 Tarragona (Spain) \\ Phone: 0034 977257891, e-mail: juancarlos.bruno@urv.cat
}

\begin{abstract}
This paper deals with the performance of a microturbine connected to a LV grid during different transient events in the network. The study is based on the dynamic modelling of a microturbine and the simulation of different events in the Matlab/Simulink environment.

The microturbine model has been validated with the measurements taken in several test of a real $28 \mathrm{~kW}$ Capstone microturbine.
\end{abstract}

\section{Keywords}

Microturbine, dynamic modelling, transient simulation, Matlab/Simulink, LVRT

\section{Introduction}

The application of micro gas turbines (MGT) in microgrids has some advantages over other competing technologies: they are lightweight and compact, have low noise levels and are vibration free. Additionally, the emissions are low, the heat recovery system is less complex than other engines, and can operate burning different fuels [1-3]. Due to these advantages, microturbines are a promising technology for supplying the electricity, heat and cooling demands of buildings.

Microturbines can operate in stand-alone or in grid connected mode. When the operation mode is grid connected, the interaction between the microturbine and the grid has to be analysed in great detail.

The connection of the microturbine to the medium voltage (MV) or low voltage (LV) network modifies the electrical parameters of the network, affecting its control and protection system. Also, transient events occurring in the grid can cause the protection of the microturbine to operate spuriously stopping the trigeneration process till the microturbine goes to a controlled stop state and restarts again, which takes several minutes. Thus, it is important to incorporate in the microturbine control the capability to ride-trough the most common transient events so the microturbine stays connected to the grid.

The microturbine analysed in this paper is based on a Capstone C30 MGT. The Capstone C30LPNG system is a compact, ultra-low-emission generator providing up to $28 \mathrm{~kW}$ of power and $60 \mathrm{~kW}$ of heat when low-pressure natural gas is used as fuel [4].

The main objective of this paper is to analyse the performance of that microturbine connected to a low voltage grid when different transient events occur in order to study its Low Voltage Ride Trough (LVRT) capability. The analysis is made using dynamic simulations in the Matlab/Simulink environment. The paper describes the microturbine model and the electrical response during different transient events. The model has been validated with the test results of a small trigeneration system.

\section{Microturbine model}

Microturbines are small combustion turbines with very high rotational speeds (between 50,000 and 120,000 rpm) directly connected to Permanent Magnet Synchronous Generators (PMSG) in the range of 25 to $300 \mathrm{~kW}$ of installed capacity.

Figure 1 shows schematically the electrical model of the microturbine. The model developed in this paper takes into account the dynamics of the different elements and represents the behaviour of the MGT during electromagnetic and electromechanical transients.

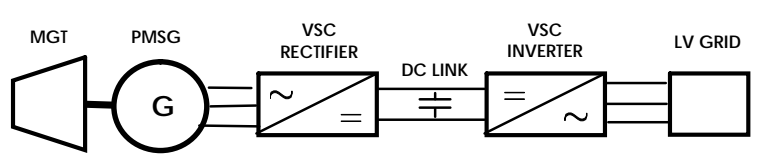

Fig. 1. Simplified electrical model. 

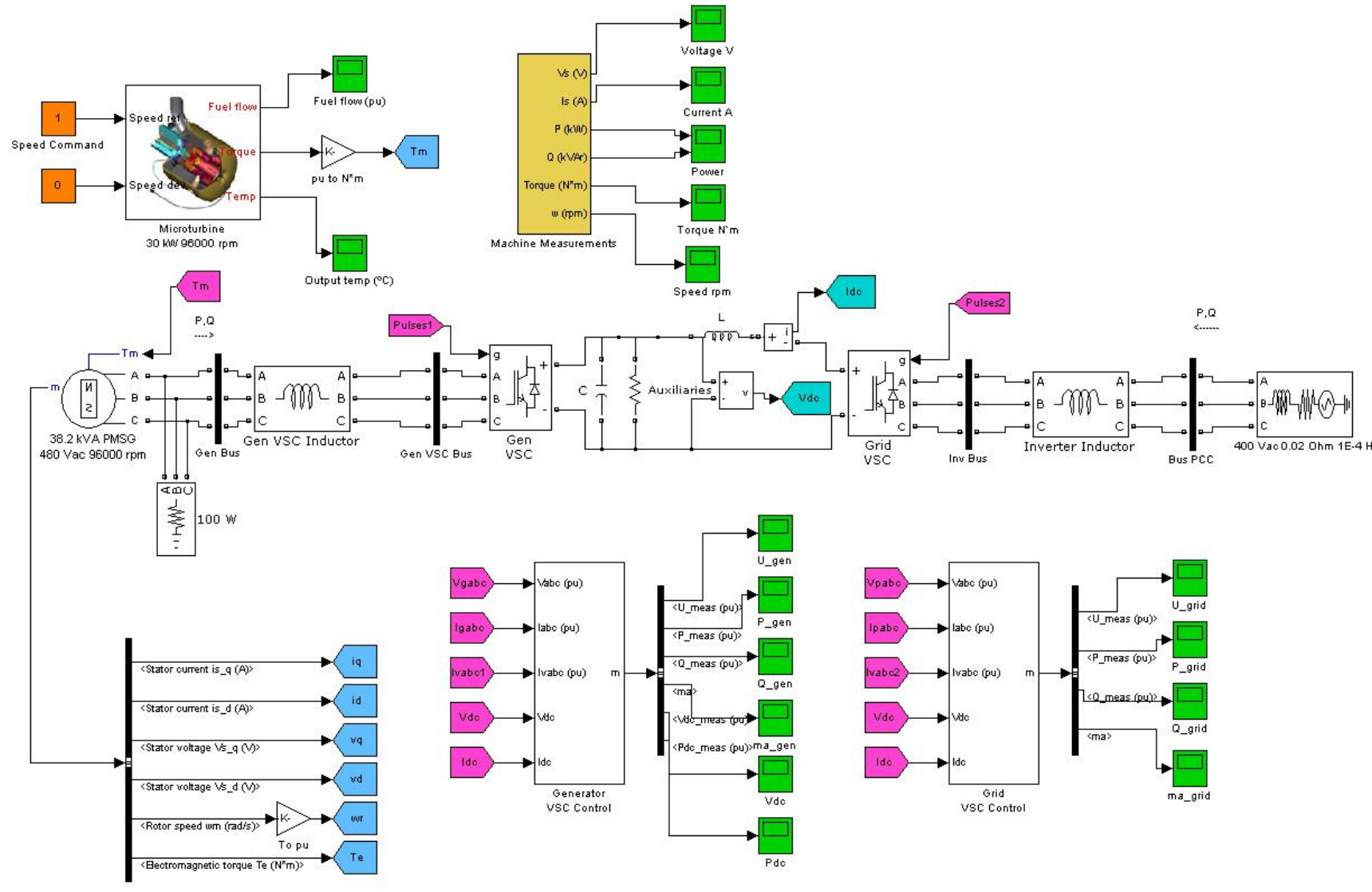

Fig. 2. Complete microturbine electrical model in Simulink.

The model includes the prime mover with speed and temperature controls, the permanent magnet synchronous generator and the AC/DC/AC power conversion system with the controls for interconnecting the high speed PMSG with the $50 \mathrm{~Hz}$ Low Voltage grid.

The complete electrical model is shown in Figure 2 and it has been developed using the toolbox SimPowerSystems [5] designed for the Matlab/Simulink environment. The different components of the model are explained with more detail in the following sub-sections

\section{A. Prime mover}

The prime mover has been modelled using a simplified single shaft gas turbine to represent its dynamics. The model has been adapted from [6] and is based on the model developed by Rowen in [7] for heavy duty gas turbines. Figure 3 shows the microturbine model.

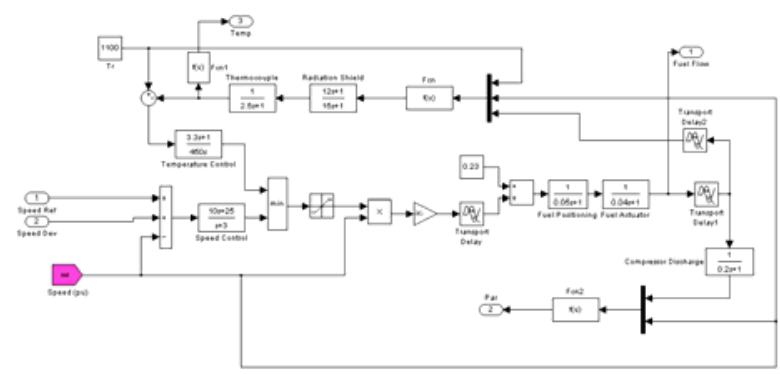

Fig. 3. Primer mover model with speed and temperature controls in Simulink.
In this model, only speed and temperature control have been taken into account. Acceleration control has been neglected as it is only used during start-up transients.

The speed control acts on the difference between the speed reference command and the rotor speed. It is the main control during part load operation. The temperature control acts as an upper power output limit. The temperature reference has been adjusted according to manufacturer data [4].

\section{B. PMSG}

The electrical generator is a high speed permanent magnet synchronous generator (PMSG) and it has been modelled using a 5th order model in the d-q reference frame [8]. The three equations of the electrical part assume sinusoidal flux:

$$
\begin{aligned}
& \frac{d i_{d}}{d t}=\frac{1}{L_{d}} v_{d}-\frac{R}{L_{d}} i_{d}+\frac{L_{q}}{L_{d}} p \omega_{r} i_{q} \\
& \frac{d i_{q}}{d t}=\frac{1}{L_{q}} v_{q}-\frac{R}{L_{q}} i_{q}-\frac{L_{d}}{L_{q}} p \omega_{r} i_{d}-\frac{1}{L_{q}} \lambda p \omega_{r} \\
& T_{e}=\frac{3}{2} p\left[\lambda i_{q}+\left(L_{d}-L_{q}\right) i_{d} i_{q}\right]
\end{aligned}
$$

The other two equations of the model are the mechanical equations of a rotating single shaft with the damping (friction factor) neglected: 


$$
\begin{aligned}
& \frac{d \omega_{r}}{d t}=\frac{1}{J}\left(T_{m}-T_{e}\right) \\
& \frac{d \theta}{d t}=\omega_{r}
\end{aligned}
$$

The parameters of the model are shown in Table I. They have been obtained from the manufacturer data [4] and from the experimental tests explained in section 3 .

Table I. - PMSG main parameters

\begin{tabular}{|l|c|}
\hline \multicolumn{1}{|c|}{ PARAMETER } & VALUE \\
\hline Rated Power & $38.2 \mathrm{kVA}$ \\
\hline Nominal Voltage & $480 \mathrm{Vac}$ \\
\hline Nominal Speed & $96000 \mathrm{rpm}$ \\
\hline Flux Linkage $(\lambda)$ & $0.041 \mathrm{~V} . \mathrm{s}$ \\
\hline Stator resistance $(R)$ & $0.1 \Omega$ \\
\hline Stator Inductances $\left(L_{d}=L_{q}\right)$ & $0.165 \mathrm{mH}$ \\
\hline Rotor Inertia $(J)$ & $0.0012 \mathrm{~kg} . \mathrm{m}^{2}$ \\
\hline
\end{tabular}

\section{Power converter}

The electronic power converter consists of two Voltage Source Converters (VSC) and a DC link. Each VSC is modelled as a three arm six pulses IGBT converter using Pulse Width Modulation (PWM) technology. Their main characteristics are shown in Table II.

Table II. - VSC main characteristics

\begin{tabular}{|l|c|c|}
\hline & $\begin{array}{c}\text { Generator } \\
\text { Converter }\end{array}$ & $\begin{array}{c}\text { Grid } \\
\text { Converter }\end{array}$ \\
\hline Power Rating & $38.2 \mathrm{kVA}$ & $32.1 \mathrm{kVA}$ \\
\hline AC Nominal Voltage & $480 \mathrm{Vac}$ & $400 \mathrm{Vac}$ \\
\hline DC Nominal Voltage & $760 \mathrm{Vdc}$ & $760 \mathrm{Vdc}$ \\
\hline Switching Frequency & $28800 \mathrm{~Hz}$ & $1350 \mathrm{~Hz}$ \\
\hline AC Inductor & $0.15 \mathrm{mH}$ & $0.53 \mathrm{mH}$ \\
\hline
\end{tabular}

In normal operation, the generator converter acts as a rectifier and the grid converter operates as an inverter. The pulses are generated by the converter control, which has been implemented in the $\mathrm{d}$-q reference frame adapted from [8].

Figure 4 shows the complete Simulink model of the converter controller. Initially, the voltages and currents are passed through an anti-aliasing filter and the AC values are then converted from "abc" to "dq0" axis using a phase lock loop to synchronize the converter with the AC frequency side. Using the "dq0" currents and voltages and the DC values, the active and reactive power and the DC voltage and power values are calculated. All the values are passed through a second order filter with a cut-off frequency of $17 \mathrm{~Hz}$ to discard high frequency noise in the measures. The filtered values are used for the control loops.

The converter has two control loops, an inner current control loop and an outer active and reactive power and DC voltage control loop.

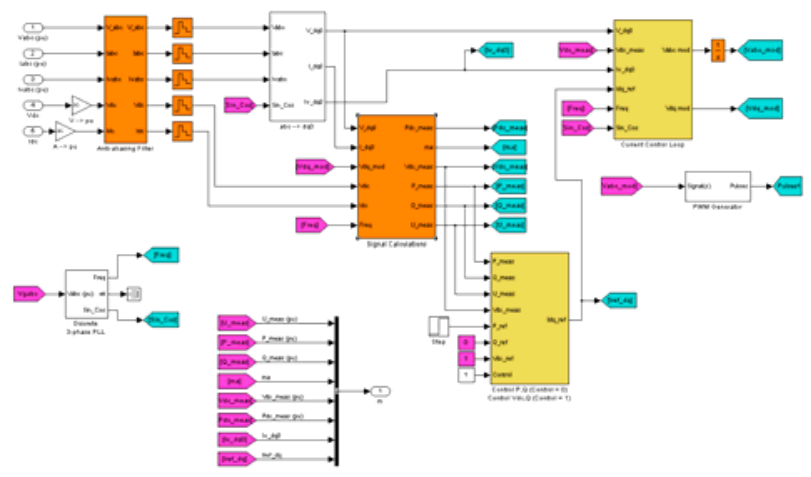

Fig. 4. Simulink model of the VSC controller.

The outer control loop calculates the d-q current references for the inner current control loop. The $d$ current reference is calculated using the output of a PI controller that follows an active power set point or a DC voltage set point. The generator controller follows a DC voltage reference point and the grid controller follows an active power set point. The $\mathrm{q}$ current reference is calculated always using a reactive power PI controller. The outputs of the controllers are limited (Figure 5).
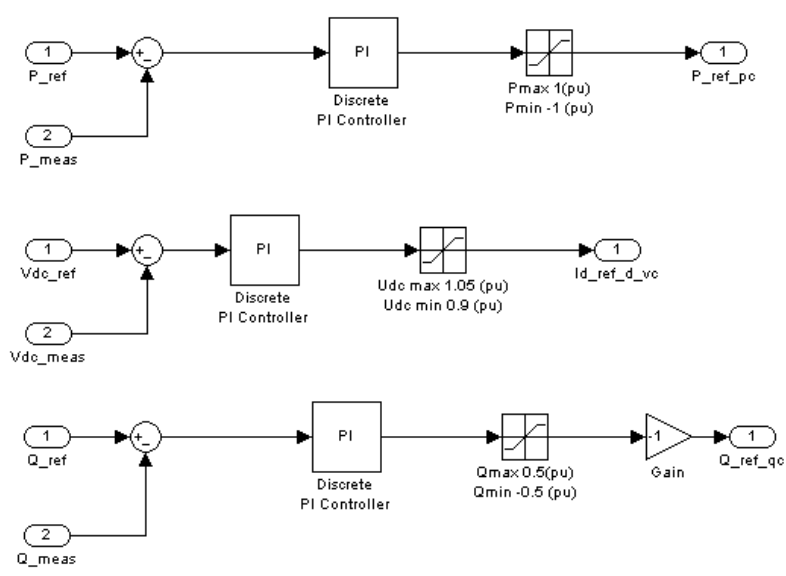

Fig. 5. P, Q and Vdc PI controllers.

The output of the P and Q controllers are converted to $i_{d}$ and $\mathrm{i}_{\mathrm{q}}$ references using the AC measured voltage (Figure 6 ) and taking into account the converter current limits.

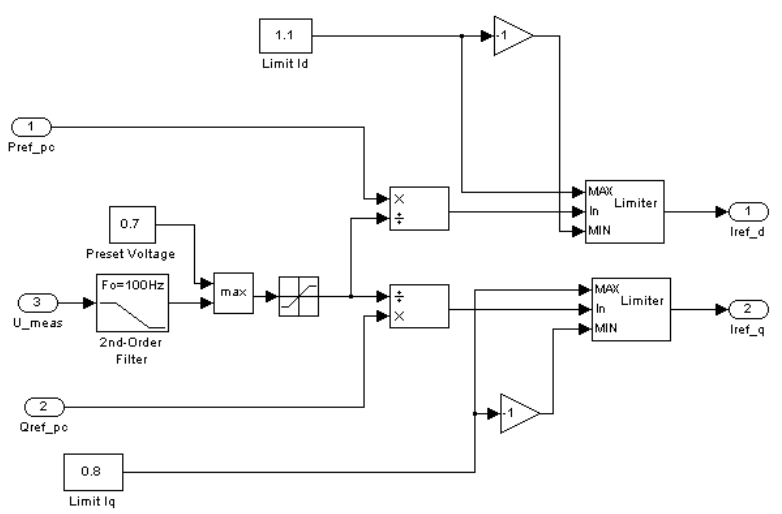

Fig. 6. Current reference calculation.

The inner control loop follows the $\mathrm{d}$ and $\mathrm{q}$ current reference using a PI controller for each reference and outputs the d-q components of the AC reference voltage (Figure 7). 


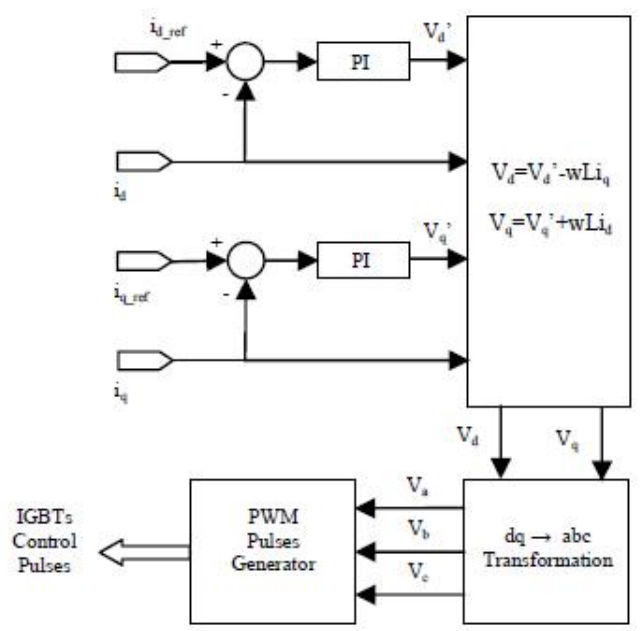

Fig. 7. Current control loop.

Finally, the d-q reference voltage is limited to 1 p.u. to avoid over-modulation, and then it is converted back to the "abc" axis. These voltages are used to generate the PWM pulses for the IGBTs of the converter.

\section{Low voltage grid}

The LV grid has been modelled using a $400 \mathrm{~V} 50 \mathrm{~Hz}$ stiff voltage source with $0.02 \Omega$ resistance and $0.01 \mathrm{mH}$ inductance, in accordance with [4].

\section{Model validation}

\section{A. Microturbine test bench}

To validate the model, the results of several experimental test performed in CREVER's new test bench, at the Rovira i Virgili University in Tarragona, have been used. The test bench allows testing different trigeneration systems under controlled environmental conditions.

The system tested is shown in Figure 8, and consist of a Capstone C30 microturbine connected to the local LV grid and a Robur ACF 60-00TK absorption chiller.

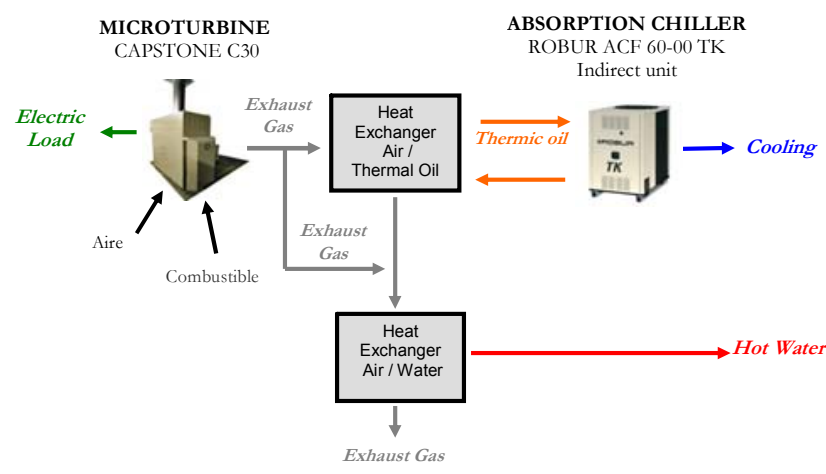

Fig. 8. Trigeneration configuration tested

The heat contained in the exhaust gas of the microturbine is recovered using an exhaust gas/thermal oil heat exchanger that drives the chiller. A second heat exchanger recovers the remaining exhaust gas heat to produce hot water.

A comprehensive database of system conditions was obtained from the test program so that the system performance could be analysed [1]

\section{B. Model simulation vs. measurements}

The measurements taken by the SCADA of the microturbine [10] have been compared with the simulation results for different steady state conditions corresponding to different active power values injected into the LV grid (power demand command). During the experimental analysis, the power demand command was changed in steps from $23 \mathrm{~kW}$ to $2 \mathrm{~kW}$. In all the experimental tests, the power factor in the point of common coupling with the grid was 1 .

The parameters of the model have been tuned in order to validate the results of the simulations with the experimental measurements. As an example, Figure 9 shows the comparison between simulation and measurements, for the rotor speed and the PMSG output, when the microturbine injects $18 \mathrm{~kW}$ into the grid.

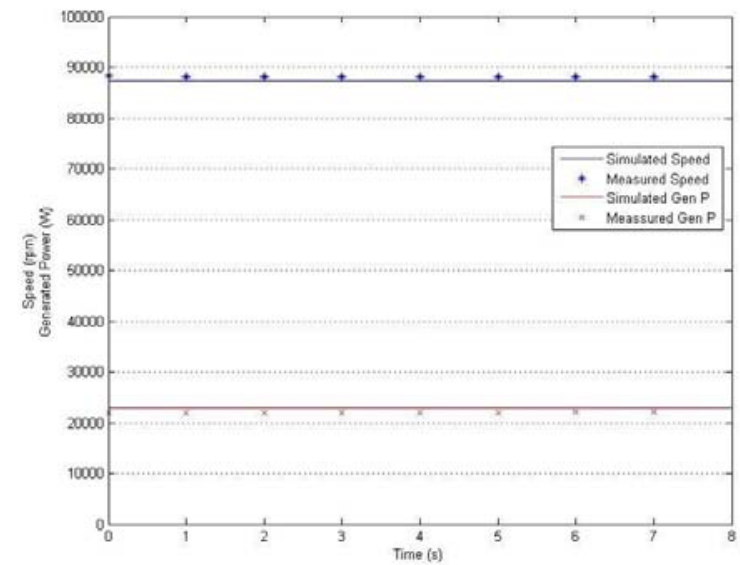

Fig. 9. PMSG power generation (W) and rotor speed (rpm) for a power demand reference of $18 \mathrm{~kW}$.

The generator output measured is close to $23 \mathrm{~kW}$, due to the demand of the auxiliaries of the microturbine. This demand depends on the output power injected into the grid but it has been considered as a constant load in the model. With this assumption, the error in the power produced by the generator is less than $5 \%$ while the error in speed is less than $1 \%$.

For other electrical quantities the error between simulation and measurements are lower. For example, Figure 10 shows the DC bus voltage and the active power exported to the grid. The error committed in the simulation of the voltage is less than $0.6 \%$, while the error in the simulation of the power injection is less than $0.4 \%$.

The results of this comparative analysis are considered good enough to validate the simulation model. 


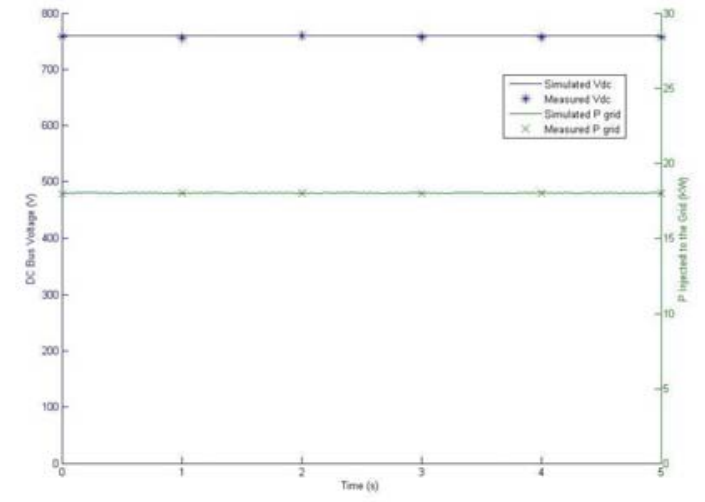

Fig. 10. DC bus voltage and active power injection for a power demand reference of $18 \mathrm{~kW}$.

\section{Transient response during grid events}

When the microturbine is connected to a low voltage grid, or to a micro-grid, it is subjected to several transient events. These events can be caused by changes in the active and reactive power commands, mandated by a load controller, in response to a change in the load. Other types of faster transients are caused by faults in the network close to the location of the microturbine, or by voltage sags due to faults in the medium voltage grid. The following subsections analyse the response of the microturbine modelled in the previous sections to this type of events.

\section{A. Power reference tracking}

During normal operation the most common transient applied to the microturbine is the change in the operating point initiated by a load following controller that reacts to changes in the load in the network. As an example, the Figure 11 shows the response of the microturbine to a step change in the active and reactive power commands.

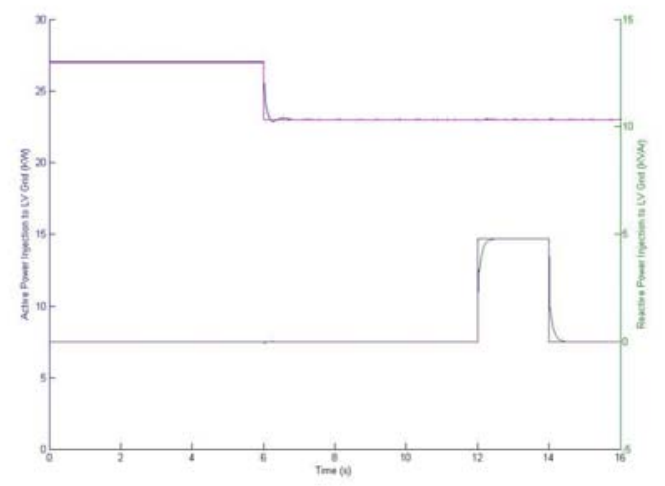

Figure 11: Microturbine response to step changes in the active and reactive power dispatch.

The simulation starts with the microturbine exporting 27 $\mathrm{kW}$ to the grid with unity p.f. At time $6 \mathrm{~s}$ the reference is changed to $23 \mathrm{~kW}$. The response of the controller achieves steady state in $1.5 \mathrm{~s}$. Later, at time $12 \mathrm{~s}$ the reactive power command is changed to $4.77 \mathrm{kVAr}$ exporting, which corresponds to 0.98 leading p.f. The response of the controller is faster, close to $500 \mathrm{~ms}$, as the primary speed control of the microturbine is not affected.
After $2 \mathrm{~s}$ the reference comes back to unity p.f. with a similar fast response. During these transients, the voltage in the DC bus changes according to Figure 12. Only the change in the active power command produces a substantial change in the voltage, around $2.5 \%$, but well bellow the overvoltage protection limit.

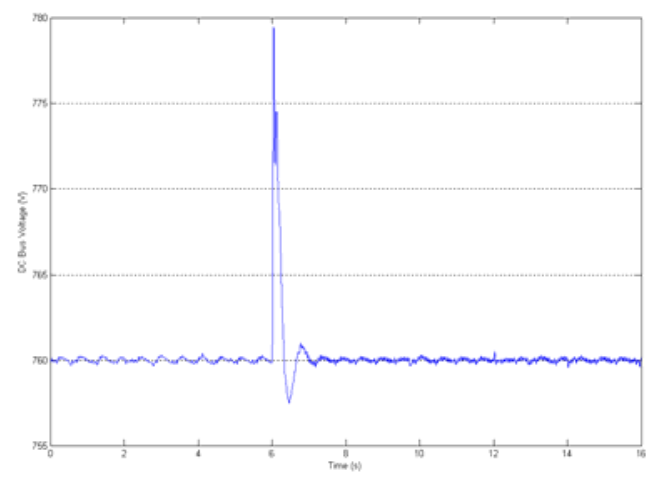

Fig. 12. Variation of the DC Bus voltage to step changes in the active and reactive power references.

For step changes in the active power command bigger than the one previously shown, the overvoltage in the DC bus can cause a protection trip and the disconnection of the microturbine. To overcome this problem a ramp limit has to be introduced in the active power control loop.

Another solution is to include a battery in the DC bus and a battery controller that acts as a chopper to maintain the voltage within limits during the transients. It has not been possible to evaluate this solution, as the tests described in section 3 have been performed with the battery pack of the microturbine disconnected.

\section{B. Network faults}

A network fault close to the point of connection of the microturbine causes a severe transient which is difficult to ride though by the microturbine. Figure 13 shows the variation in the rotor speed for a close three phase bolted fault of $150 \mathrm{~ms}$ duration, when the microturbine is exporting $23 \mathrm{~kW}$ to the grid with unity p.f.

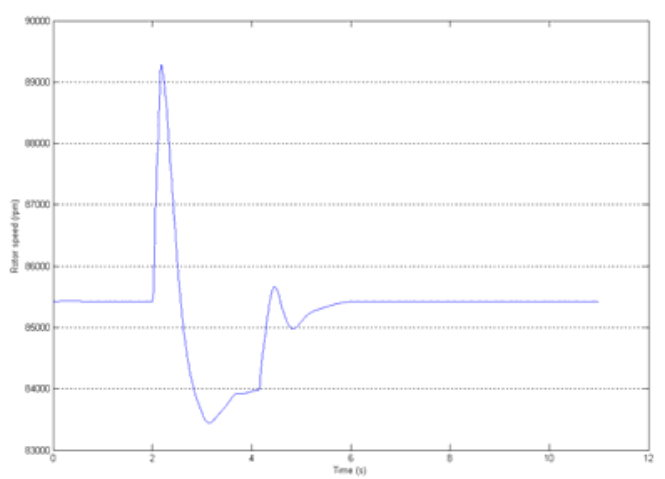

Fig. 13. Rotor speed variation for a close 3 phase bolted fault of 150 ms duration.

During the fault the speed rises $4.7 \%$ but stays bellow the over-speed limit. After $4 \mathrm{~s}$ the machine returns to the prefault state. The problem is with the voltage in the DC Bus (Figure 14). During the fault a short duration spike of 
19.3\% appears, but before the recovery to pre-fault level a more severe overvoltage, reaching $40.5 \%$, appears. The voltage stays over $10 \%$ for $220 \mathrm{~ms}$ which will cause the overvoltage protection to trip.

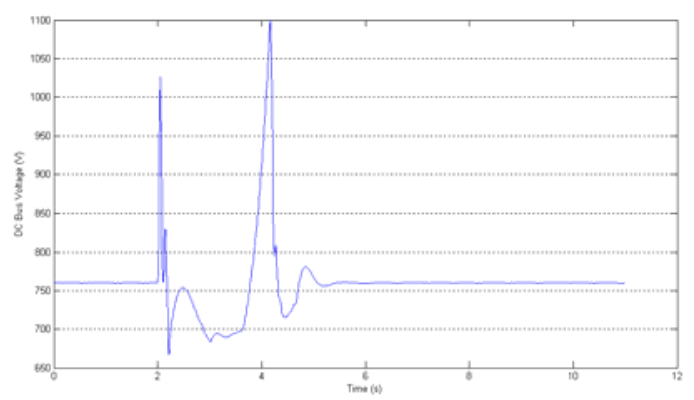

Fig. 14. DC Bus voltage variation for a close 3 phase bolted fault of 150 ms duration.

To overcome this problem, a chopper is needed to absorb the excess energy in the DC bus during the transient. As it has been stated before it has not been possible to evaluate this due to the configuration of the Capstone C30 during the tests.

\section{Voltage sags}

Voltage sags in LV grids, caused by faults in the MV grid, are very common. These sags cause a transient in the microturbine but less severe than for close three phase faults. Figure 15 shows the variation in DC bus voltage caused by a voltage sag of $50 \%$ and $300 \mathrm{~ms}$ duration.

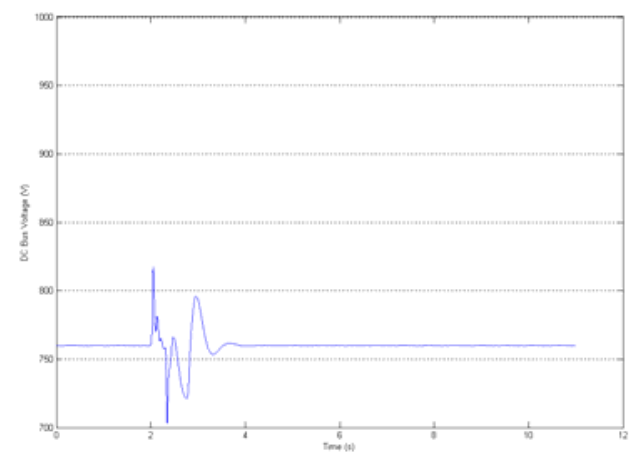

Fig. 15. DC Bus voltage variation for a 50\% sag of $300 \mathrm{~ms}$ duration.

In this case, the voltage rises $7.5 \%$ but stays bellow the over-voltage trip level.

\section{Conclusions}

Micro gas turbines are a promising technology for supplying the electricity, heat and cooling demands of buildings, contributing to an increase in energy efficiency. The microturbines are connected to the LV grid acting as a fixed energy source or a controlled power source within an electrical microgrid.

To avoid interruptions in the supply of heat and cool, the microturbine must withstand the electromagnetic transients caused by common events in the network, as faults and voltage sags. This paper analyses the transient response of a microturbine to these types of events. The studies are based on simulation of the microturbine with a detailed model of the controls, and the validation of the model with laboratory test of a commercial microturbine.

The simulations show that the weakest part during the transients is the DC bus, which is subjected to overvoltages due to an excess of energy that can not be evacuated to the grid. The operation of the overvoltage protection limits the capability of the microturbine to ride through the fault. To improve the LVRT capability, a chopper must be installed in the DC bus. This aspect is currently under evaluation as new laboratory test have to be made to the capstone C30 microturbine, with the battery pack installed and battery controller in operation, to tune the model with the chopper included.

\section{Acknowledgements}

The authors would like to acknowledge the funding for this work provided by the Ministry of Industry, Commerce and Tourism of Spain, Plan Nacional de I+D+I, TRIGENED Project, ENE2006-15700-C02$01 / \mathrm{CON}$.

\section{References}

[1] M. Moya, D. Martínez, M.A. Marimon, J.C. Bruno, A. Coronas, P. Eguia, E. Torres, I. Zamora, "Modeling and experimental evaluation of a trigeneration system with a microturbine and an indirect fired absorption chiller driven by exhaust gases”, in Proc. SIMS50, 7-8 October 2009, Fredericia (Denmark)

[2] J.I. San Martín, I. Zamora, J.J. San Martín, V. Aperribay, P. Eguia, "Trigeneration Systems with Fuel Cells", in Proc. ICREPQ’08, 12-14 March 2008, Santander (Spain).

[3] E. Torres, J.M. Larragueta. P. Eguia, A.J. Mazón, J.I. San Martín, I. Zamora, "Dynamic Performance of a Microturbine Connected to a Low Voltage Network", in Proc. ICREPQ'08, 12-14 March 2008, Santander (Spain).

[4] "Capstone Model C30 MicroTurbine Technical reference. Component description”, Ref. 410014-001 Rev B, August 2003. See also: http://www.capstoneturbine.com

[5] Hydro-Québec, "SimPowerSystems 5 User’s Guide”, 3 Apple Hill Drive, Natick, MA, USA. See also: http://www.mathworks.com/products/simpower/

[6] Gaonkar D.N., Patel R.N., "Dynamic Model of Microturbine Generation System for Grid Connected/Islanding Operation”, in Proc. ICIT 2006, pp. 305-310, 15-17 December 2006, Mumbai (India).

[7] Rowen R.I., "Simplified mathematical representations of heavy duty gas turbines", Journal of Engineering for Power, Transactions ASME, vol. 105, no. 4, pp. 865-869, Oct, 1983.

[8] Casoria S, "VSC-Based HVDC Transmission System”, in SimPowerSystems 5 User’s Guide.

See also: http://www.mathworks.com/products/simpower/

[9] "Capstone Model C30 MicroTurbine Technical reference. Capstone Remote Monitoring System (Maintenance Edition)”, Ref. 410014-001 Rev A, July 2002.

See also: http://www.capstoneturbine.com 